\title{
PERFORMANCE ANALYSIS OF PRIORITY SCHEME IN ATM NETWORK
}

\author{
Vikram Bali
}

\author{
Rajkumar Singh Rathore \\ Department of Computer Science \& Engineering \\ Ideal Institute of Technology, Ghaziabad
}

Amit Sirohi

\begin{abstract}
The asynchronous Transfer Mode (ATM) is the widely used packet switching and connection oriented technology that meets diverse services and performance requirements of real time applications using the broadcast. An ATM network is suitable for multimedia services with different traffic flow characteristics and quality of services (QoS ) requirements. In order to meet the required QoS of each traffic type, some types of priority disciplines are needed in packet switching to increase the utilization of switches in ATM networks. This paper describes a buffer management scheme using two different prioritized service disciplines in order to improve the QoS in terms of cell delay time for each traffic class and to reduce the cell loss rate of loss sensitive class in an ATM network. The performance analysis and comparative study of these priority schemes have been presented.
\end{abstract}

\section{INTRODUCTION}

broadband integrated services digital network (B- ISDN) is designed to support and accommodate a wide variety of service demands such as voice, data, video and their possible combinations in a flexible manner, both at the level of individual and the system as a whole $[1,2]$. Asynchronous Transfer Mode (ATM) is a cell oriented transfer mode based on fixed size calls and accepted universally as the transfer mode of choice for B-ISDN. ATM technology is suitable to support high speed multimedia services with diversified traffic flow characteristics and QoS requirements because it provides flexibility in bandwidth allocations through the assignment of fixed length packets. In an ATM network, various types of traffic are statistically multiplexed to efficiently utilize the network resources. However, the excessive use of the bandwidth may cause traffic dependent QoS deteriorations, such as cell delay and cell loss at the buffer for different traffic classes [18,19].

In order to maintain the QoS of ach traffic type, some types of priority schemes are required to use in scheduling process at switching node in an ATM network. These priority schemes treat each traffic class according to its QoS requirements and support -integrated services $[3,10,15,16]$

In this paper two types of priority schemes namely - arrival Rate Based State Dependent (ARBSD) priority scheme and the Relative State Dependent (RSD) Priority schemes have been analyzed for the scheduling of an output buffered ATM switch $[3,4]$. In the ARBSD priority scheme the number of cells of each traffic class in the buffer and its corresponding arrival rate to decide, which class is selected for service in the next time slot? In the RSD priority scheme, the decision of next services is based only on the number of cells in each class.

The service discipline of the ARBSD priority scheme is described as follows: Suppose the number of delay sensitive cells and loss sensitive cells in the output buffered switch at time slot $n$ are $Q_{d}(n)$ and $Q_{1}(n)$ and the average arrival rate for the delay sensitive class and the loss sensitive class are $\mathrm{P}_{\mathrm{d}}$ and $\mathrm{p}_{1}$ respectively. Let $\mathrm{R}$ be an adjustable parameter, which is used to control the delay time of each traffic class.

If the condition $\left.\left[(\mathrm{Q}(\mathrm{n}) / \mathrm{p} 1) / \mathrm{Q}_{\mathrm{d}}(\mathrm{n}) / \mathrm{p}_{\mathrm{d}}\right)\right]=\mathrm{R}$ is held, the delay sensitive cell is selected for service otherwise loss sensitive cell is selected for service $[3,4,17]$.

The RSD priority scheme is described as: If the condition $\left[\left(\mathrm{Q}(\mathrm{n}) / \quad \mathrm{Q}_{\mathrm{d}}(\mathrm{n})\right]=\mathrm{R}\right.$ is held the delay sensitive class is selected for service, otherwise, the loss sensitive class is selected for services $[3,4,17,19]$.

\section{SYSTEM DESCRIPTION}

System, considered in this paper, is assumed to be an $\mathrm{N} \times \mathrm{N}$ ATM switch with output buffer as shown in fig. 1. Each output port has a buffer of size B, where cells arrive in batches. From QoS point of view, services can be classified into two categories, i.e., delay sensitive (DS) services and loss sensitive (LS ) services. The DS services are those, which have stringent delay and delay variation requirements (e.g. voice and video (real time )services . The LS services have stringent cell loss requirement (e.g. compressed video, data transfer). So we have cell delay. Cell delay variation and cell loss rate as QoS parameters.

The buffer architecture, as shown in fig. 2. is used to reduce the cell loss rate for los sensitive class. Two pointers are used to po9int the position of the arrived priority cells. The 
arriving DS cells are placed into the buffer from right to left by right pointer, whole the arriving LS cells are placed into the buffer from left to right by left pointer respectively. . When the buffer is full, pointer are next to each other. Under this situation, any DS cell arrival is discarded, but a LS cell arrival will be stored by replacing a DS cell in the buffer.

\section{PERFORMANCE ANALYSIS}

In this section the average delay time and cell loss rate for each class of traffic using the above -discussed two priority schemes are analyzed. We assume that cell arrival at each input is used as a heuristic approach to Poisson process begins with Bernoulli trials with traffic load P[17]. Each incoming cell is equally appearing at any of the $\mathrm{N}$ output po9rts. Here, traffic load $\mathrm{p}$ means arrival rate for $\mathrm{N}$ input lines. So arrival rate or traffic load for each input line becomes $(\mathrm{p} / \mathrm{N})$

We consider only one port $\mathrm{j}$ to simplify the analysis because the performance of each output buffer in the switch is the same. The total number of cells appeared for output port $\mathrm{j}$ at time slot $\mathrm{n}$ is denoted by $\mathrm{A}(\mathrm{n})$. For a switch operating $\mathrm{N}$ times the speed of the input line, the batch arrival size for output port $\mathrm{j}$ is limited to N. The Probability of $\mathrm{k}$ successes in $\mathrm{N}$ trials [17].

\subsubsection{ANALYSIS FOR THE ARBSD AND RSD PRIORITY SCHEMES}

Let $A_{d}(n)$ and $A_{1}(n)$ demote the number of delay sensitive cells reaching output port $\mathrm{j}$ in time slot $n$.

Let $\mathrm{P}_{\mathrm{d}}$ be the probability that an incoming cell is a delay sensitive one. The average arrival rate for delay sensitive class is $\mathrm{p} \mathrm{P}_{\mathrm{d}}$ and the arrival rate for loss sensitive class is $\mathrm{p}$ (1-p)

Let $d_{k}=\operatorname{Pr}\left[A_{d}(n)=K\right]$

$\mathrm{K}$ delay sensitive arrivals would mean that there are at least $\mathrm{k}$ total arrivals at the output port.

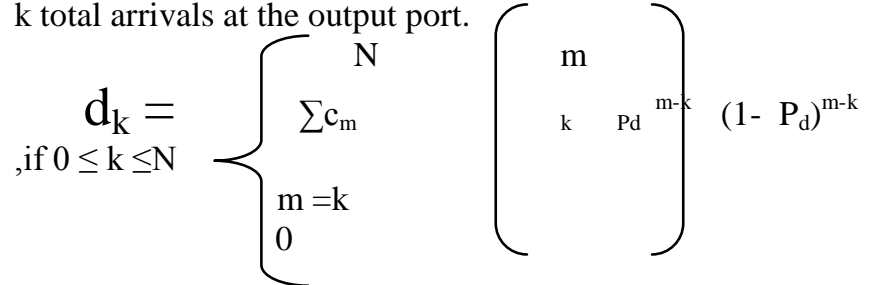

$\mathrm{k}$ loss sensitive arrivals would mans that there are at least $\mathrm{k}$ total arrivals at the output port

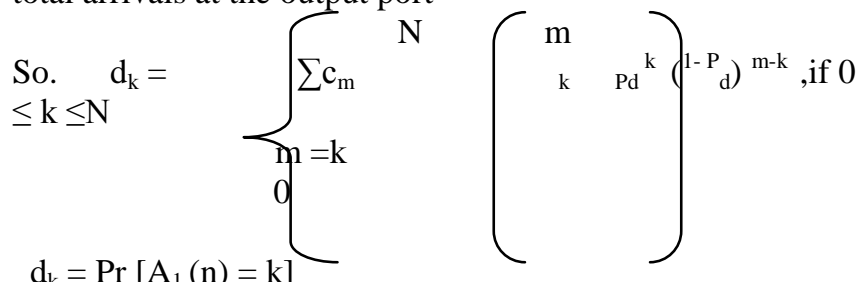

Let $\mathrm{Q}_{1}(\mathrm{n})$ denote the number of delay - sensitive cells and loss -sensitive cells in the buffer at the end of the $n^{\text {th }}$ time slot. In out case, if the queue is not empty in the current time slot then one of the cells will be transmitted in the next time slot. Thus we have

$$
\begin{aligned}
& \mathrm{Q}_{1}=\quad \operatorname{mine}\left\{\mathrm{B}, \mathrm{Q}_{1}\left(\mathrm{n}-1+\mathrm{A}_{1(\mathrm{n})}-1\right\}\right. \text { if } \\
& {\left[\frac{Q 1(n-1 /) / p L}{Q d(n-1) / p d}\right]>\mathrm{R}} \\
& \operatorname{mine}\left\{\mathrm{B}, \mathrm{Q}_{1}\left(\mathrm{n}-1+\mathrm{A}_{1(\mathrm{n})}\right\} \quad\right. \text { otherwise } \\
& \mathrm{Q}_{\mathrm{d}}=\quad \operatorname{mine}\left\{\mathrm{B}, \mathrm{Q}_{1}(\mathrm{n}-1)+\mathrm{A}_{1(\mathrm{n})}-1\right\} \text { if } \\
& {\left[\frac{Q 1(n-1 /) / p L}{Q d(n-1) / p d}\right] \leq \mathrm{R}} \\
& \operatorname{mine}\left\{\mathrm{B}, \mathrm{Q}_{1}(\mathrm{n}-1)+\mathrm{A}_{\mathrm{d}(\mathrm{n})}\right\} \\
& \mathrm{Q}_{\mathrm{d}}=\quad \text { mine }\left\{\mathrm{B}, \mathrm{Q}_{1}(\mathrm{n}-1)+\mathrm{A}_{1(\mathrm{n})}-1\right\} \text { if } \\
& {\left[\frac{Q 1(n-1 /) / p L}{Q d(n-1) / p d}\right] \leq \mathrm{R}} \\
& \operatorname{mine}\left\{\mathrm{B}, \mathrm{Q}_{1}(\mathrm{n}-1)+\mathrm{A}_{\mathrm{d}(\mathrm{n})}\right\}
\end{aligned}
$$

From these equations we find that the system state $\left[Q_{d}(n)\right.$, $\left.\mathrm{Q}_{1}(\mathrm{n})\right]$ at $\mathrm{n}^{\text {th }}$ time slot depends only on the system state at the $(n-1)^{\text {th }}$ time slot $\left[\mathrm{Q}_{\mathrm{d}}(\mathrm{n}), \mathrm{Q}_{1}(\mathrm{n})\right]$ at $\mathrm{n}^{\text {th }}$, thus a two dimensional Markov Chain forms. The state transition probability between any two system states is denoted as T $(\mathrm{j}, \mathrm{m} ; \mathrm{I}, 1)$ and can be defined as

$$
\begin{array}{r}
Q_{1}(n)=, J Q_{1}(n)=m \\
T(j, m ; i, 1)=P\left[Q_{1}(n-1)=i, Q_{1}(n-1)\right]
\end{array}
$$

The steady state distribution $P(i, m)$ is defined as $P(j, m)=\lim \left[Q_{d(n)}=j Q_{1}(n)=m\right]$

The stationary distribution $\mathrm{P}(\mathrm{I}, \mathrm{m})$ is obtained by solving the state balance

Equation, $P(j, m)=\sum_{J=0 j=} \sum_{\text {B }}^{\text {B }-1} \quad$ T (j, m: I, 1 P (I,l)

And the normalizing equation

$$
\sum_{j}^{B} \sum^{B}-1
$$


By solving the steady state $\mathrm{P}(\mathrm{i}, \mathrm{m})$ using these above equations, we obtain the steady state distribution for delay sensitive class and loss sensitive class $P_{d}(j)$ and $P_{1}(m)$ respectively as,

$$
\begin{aligned}
& \mathrm{P}_{\mathrm{d}}=\sum_{\mathrm{m}=0}^{\mathrm{B}-1} \mathrm{P}(\mathrm{j}, \mathrm{m}) \\
& \mathrm{P}_{1}=\sum_{\mathrm{j}=0}^{\mathrm{B}-\mathrm{m}} \quad(\mathrm{j}, \mathrm{m})
\end{aligned}
$$

Now , average number of delay sensitive cells in the queue is

$$
\bar{Q}_{\mathrm{d}} \sum_{\mathrm{j}=1}^{\mathrm{B}} \quad \mathrm{jP}(\mathrm{j})
$$

Similarly the average number of loss sensitive cells in the queue is

$$
\bar{Q}_{\mathrm{d}}=\sum_{\mathrm{m}=1}^{\mathrm{B}} \mathrm{mP}_{1}(\mathrm{j})
$$

Now we proceed to find the average number of loss sensitive cells lost in a time slot, the cell loss rate and the waiting time for the same.

Let, there be $\mathrm{m}$ loss sensitive cells in the queue and $\mathrm{K}$ loss sensitive arrivals in the next time slot. If a loss sensitive cell is not selected for transmission, then in the next time slot, there will be $[\mathrm{k}-(\mathrm{B}-\mathrm{m})]^{+}$loss sensitive cells lost. If a loss sensitive cell is selected for transmission at the next time slot, there will be $[\mathrm{k}-(\mathrm{B}-\mathrm{m}+1)]^{+}$loss sensitive cells lost. Thus, the

Average number of loss sensitive los in a slot, denoted as $\mathrm{L}_{1}$ is given as

$$
\mathrm{L}_{1}==\sum_{\frac{j}{p d} \mathrm{R}<\frac{m}{m} \mathrm{k}=\mathrm{B}-\mathrm{\textrm {m }}=2}^{\left.\mathrm{N}, \mathrm{m}) \quad \sum 1_{\mathrm{k}}-(\mathrm{B}-\mathrm{M}+1)\right]}
$$

$$
\sum \quad \sum \quad \mathrm{P}(\mathrm{j}, \mathrm{m}) \quad \sum^{\mathrm{N}} 1_{\mathrm{k}}-(\mathrm{k}-(\mathrm{B}-\mathrm{m})]
$$

$$
\frac{j}{p d} \mathrm{R} \geq \frac{m}{m} \mathrm{k}=\mathrm{B}-\mathrm{m}+1 \mathrm{~N}
$$

So the cell loss rate for loss sensitive traffic class is

$$
\mathrm{P}_{1}^{\text {loss }}=\frac{L 1}{P 1}
$$

\section{RESULTS AND DISCUSSION}

In this section, we examine the performance of an output buffered ATM switch using the static Priority scheme and the ARBSD priority schemes and the RSD priority scheme traffic parameters namely as buffer size, the number of ports and the probability of the incoming cells, Figure 3 . Shows the delay time ratio versed arrival rate for the static priority scheme and the ARBSD, RSD priority schemes. The buffer size is 20 , the number of output port is 16 , and the probability that an incoming cell is delay - sensitive equals to $0.5\left(\mathrm{P}_{\mathrm{d}}=0.5\right)$. The control parameter $\mathrm{R}$ in the analyzed schemes is equal to 1,2 , and 4 respectively. The delay time ratio in the ARBSD priority scheme is the same as that in the RSD priority scheme because $\mathrm{P}_{\mathrm{d}}$ (Probability of delay sensitive cell arrival) is 0.5 . In the static priority scheme, the delay time ratio increases with arrival rate, but in the ARBSD in case of $\mathrm{R}=1$ ARBSD, and then it gradually approaches the value of the control parameter $\mathrm{R}$ when the arrival rate approaches 0.9. Mean while, the delay time ratio in both the ARBSD and the RSD priority scheme increase as control parameter $\mathrm{R}$ increases. When the control parameter $\mathrm{R}$ equals 1 , the delay time ratio is still greater than 1. This implies that the average delay time for delay sensitive class in smaller than the average delay time for loss sensitive traffic class. . Figure 4. shows the delay time ratio verses arrival rate with $P_{d}=0.95$. In this case the most of the traffic is delay sensitive. We find that the delay time ratio for the ARBSD priority scheme is much smaller than that in the static priority scheme. The delay time for losssensitive transitive traffic class in the ARB?SD priority scheme is smaller than that in the RSD priority scheme. The reason lies in that the arrival rate for the delay sensitive class $P_{d}$ is much larger than that of loss sensitive class.

Figure . 5 (a0 \& (b) shows delay time for delay sensitive and loss sensitive classes of traffic respectively in the ARBSD priority scheme. The average delay time for the delay sensitive class in the ARBSD priority scheme is larger than that in the static priority scheme ARBSD priority scheme is smaller than that in the static priority scheme. Thus the improvement of the delay for loss sensitive traffic class is at the expense of the delay time delay - sensitive traffic class. 
Figure 6. shows delay time ratio versus probability $\mathrm{P}_{\mathrm{d}}$ for arrival rate equal to 0.9 . the delay time ratio in the ratio in the RSD priority scheme increases monotonically. The delay time ratio in the ARBSD priory schemes decreases with $P_{d}$. Figure 7. (a) \& (b) show cell loss rate versus buffer size for loss sensitive and delay sensitive traffic classes with $\mathrm{P}_{\mathrm{d}}=0.5$. buffer soze required to get the cell loss rate for loss sensitive class in ARBSD priority scheme with $R=1$ is between 5 to 10 . Buffer size is between 10 to 15 with $R=2$ and with $\mathrm{R}=4$, buffer size is between sized is between 15 to 20 ,

In the case of static priority scheme buffer size required to achieve the loss rte for loss sensitive traffic class is between 25 to 30 .

\section{Conclusion}

We discussed and analyzed a buffer management scheme for ATM networks to allocate two different classes of traffic, which require different QoS, is simulated offer random traffic. The delay time of random traffic in the ARBSD priority scheme and the RSD priority scheme are controlled by the control parameter R. When the control parameter $\mathrm{R}$ decreases, the average delay time of the loss sensitive traffic class decreases at the expanse of average delay time of the delay sensitive traffic class for both schemes.

When most of the traffic is loss sensitive, the average delay time of loss sensitive traffic class decreases negligibly, but the average delay time for delay sensitive class increases slightly. Therefore it is less beneficial to employ the ARBSD priority scheme and the RSD priority scheme When most traffic is delay sensitive, the average delay time of loss sensitive traffic class decreases much at the expanse of average delay time of the delay sensitive traffic class. So the reduce the starvation problem of the static priority scheme. It is beneficial to use the ARBSD priority scheme and the RSD priority scheme

In the ARBSD priority scheme, the improvement of delay time is better than in the RSD priority shame. Compared to the RSD priority schema, the delay time in the ARBSD priority scheme is less sensitive to the probability $\mathrm{P}_{d}$ Thus the ARBSD priority scheme is favorable when there are different kinds of traffic mixture.

The cell loss rate of loss sensitive traffic class in the ARBSD priority scheme is better than in the static priority scheme

\section{REFERENCES}

[1]. Patrick E. White "Role of the Broadband Integrated Services Digital Network" IEEE Comm. Mgazine pp 166-199, March 1991.

[2]. Totomu Murase, Hiroshi Suzuki, shohei Sato and Takao Takeuchi ‘ A call admission control schemes for ATM networks using a simple quality estimate " IEEE journal On Selected Areas in Communications vol. 9, pp 1461-1470, Dec 1991.

[3] T. Y huange and j-L C.Wu " performance analysis of ATM switches using priority schemes" IEEE Proc. Comm. Vol 141No. 4 pp 248-254, August 1994.

[4] . T. Y Huang and j-L C. Wu "Performance analysis of prioritized state dependent buffer management schemes in ATM networks" switches using priority schemes" Computer Networks and ISDN Systems, Vol 27 No. 10pp45-66, Oct. 1994.

[5]. J.Y. Lee, C. K. UN “ Performance analysis of an input and output Queuing packet Switch with a priority packet discarding scheme IEEE Proc. Comm. Voll 142 pp 248-254 April 1995.

[6]. C, Rosenberg, F. Guillemin and R. Mazumdar "J New approach for traffic characteristics in ATM network "IEEE Proc. Comm. Vol 142pp8790, April 1995.

[7]. A. L Roginsky, L A. Tomek and K. J . Christensen “ Analysis of ATM cell loss for systems with on/off traffic sources "IEEE Proc. Comm. Vol. 144pp129-134, June 1997.

[8]. Youngho LIM, john E. Kobza " Analysis of a delay dependent priority discipline in an integrated multiclass traffic fst packet switch" IEEE transaction on comm.. Vol 38pp659-665, May 1990.

[9]. Andrian E. Eckberg, Hharat T. Doshi and Richard Zoccolillo “ Controlling Congestion in B - Magazine pp 64-70 Sept 1991.

[10]. Setialdi Yazid and H. T. Monftah "Congestion control methods for B-ISDN “IEEE Comm. Magazine pp 42-47, july 1992

[11]. Marek Wenik, Osama Aboul Magd and Henry Gilbert " Traffic management for B- ISDN services “ IEEE Network pp10-18, Sept,1992.

[12] . A. E. Eckberg " B ISDN / ATM traffic and congestion control" IEEE Network pp28-37, Sept. 1992.

[13]. Henry Gilbert, Osama Aboul Magd and Van Phung "J Depveloping a cohesive traffic management strategy for ATM network " IEEE comm.. Magazine pp 36-45, Oct. 1991.

[14]. Thomas M . Chen, jean Walrand and David G. Messerschmitt : Dynamic priority protocols packet voce : IEEE journal On Selected Areas in communication vol. 7,pp 632-643, june 1989.

[15]. Arthur Y. M. Line and john A. Sylvester "Priority quesuing strategies and buffer allocation protocols for traffic control at an ATM integrated broabd and switching system" IEEE journal on Selected Areas in Communication vol. 9. pp 1535 Dec. 1991.

[16]. Hans Kroner, Gerard Hebuterne, Pierre Boyer and Annie Gravery “ Priority management in ATM switching nodes " IEEE journal on Selected Areas in Comms. Vol. 9,pp 418-427 April 1991.

[17]. J. F. Hayes, Modeling and Analysis of Computer Communication Networks, Khanna Publication, India, , $1^{\text {st }}$ Edition 1987.

[18]. Martin De Prycker "J ATM switching on Demand " IEEE Network pp 25-28, March 1992.

[19]. Dimitri Dersekas and Robert Gallager, Data Networks, Prentice hall of India Pvt. Limited Publications, New Delhi, IV Edition, 1996. 


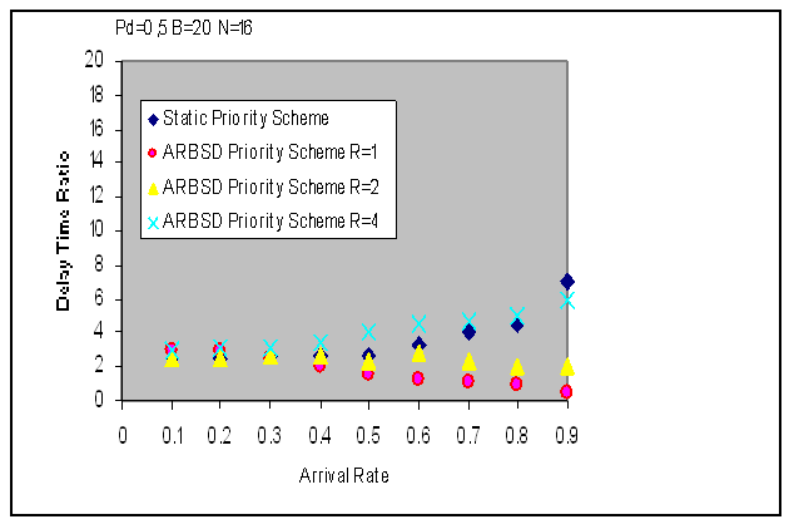

Fig. 3 Delay Time Ratio Vs Arrival Rate for Different Priority Schemes

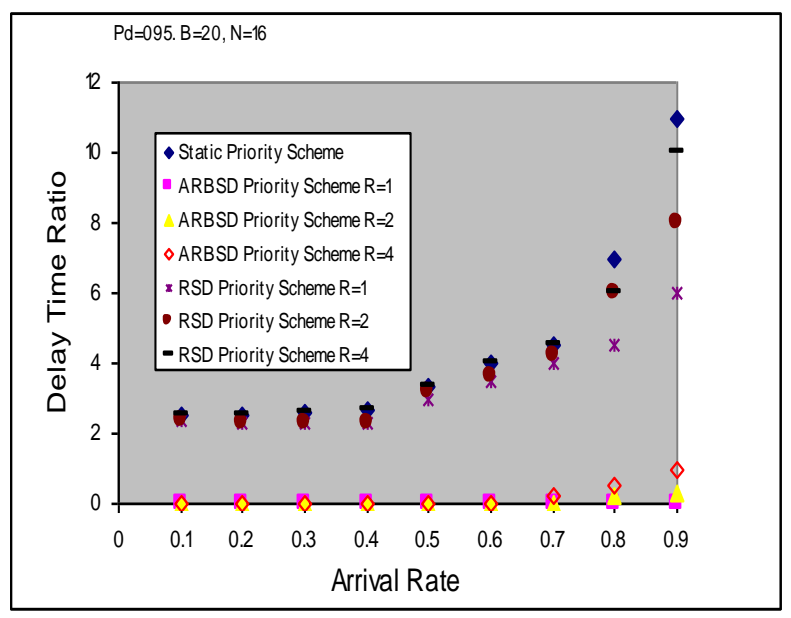

Fig. 4. Delay Time Ratio Vs Arrival Rate for different Priority schemes

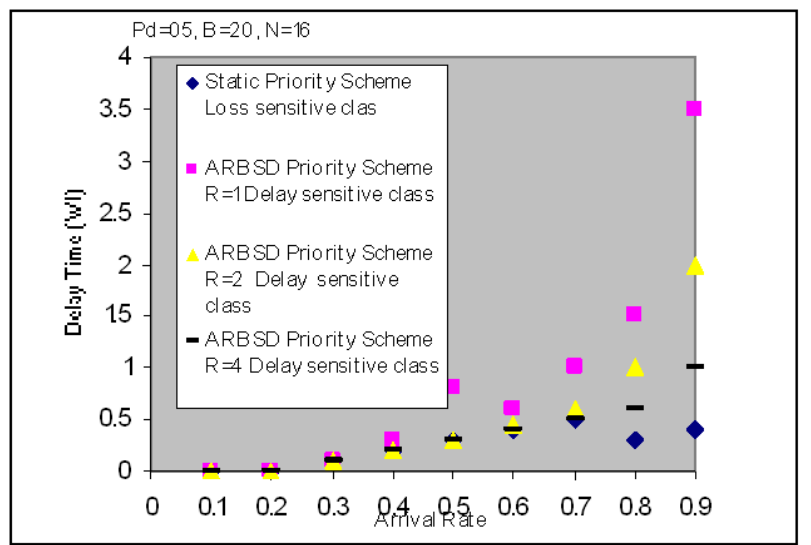

Figure 5 (a) Average Delay Time Vs Arrival Rate for different Priority Schemes

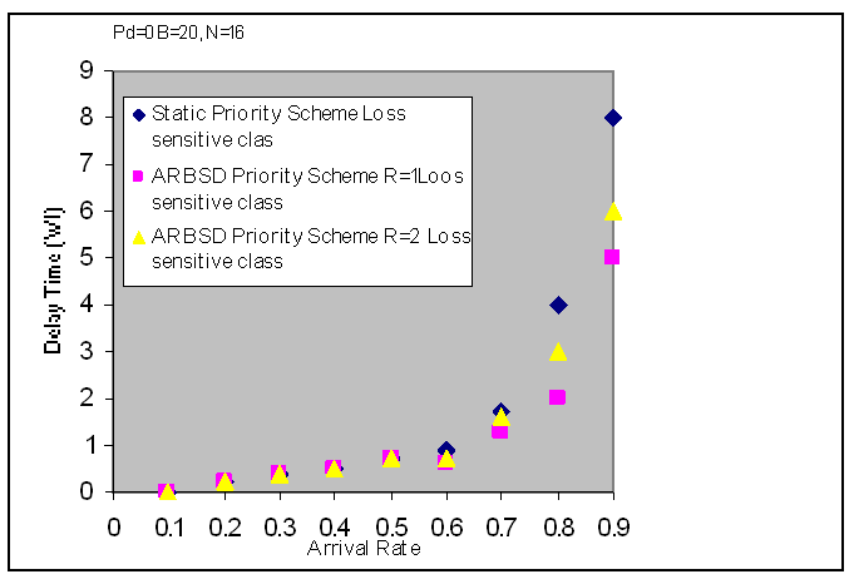

Figure 5 (b) Average Delay Time Vs Arrival Rate for different

Priority Schemes 


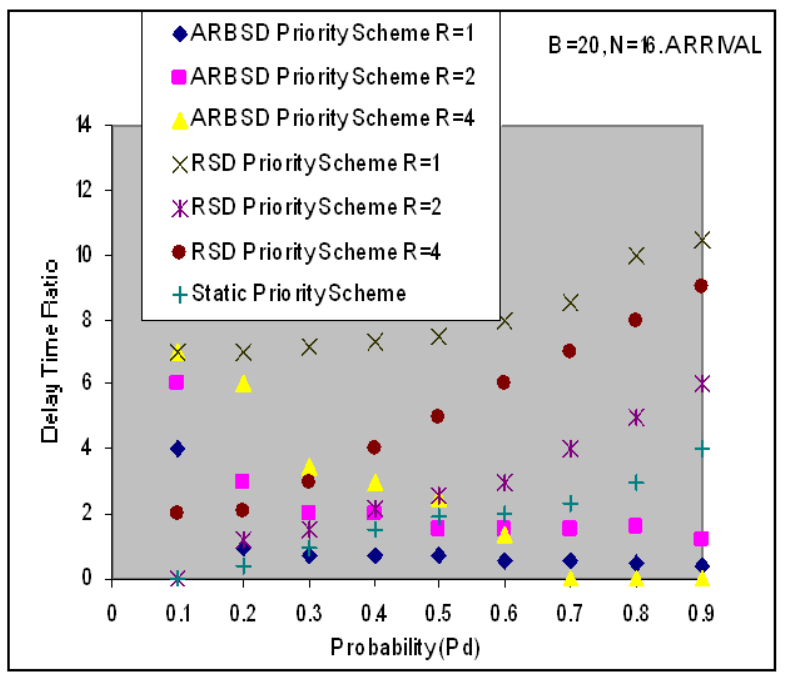

Fig. 6 Delay Time Ratio Vs Probability

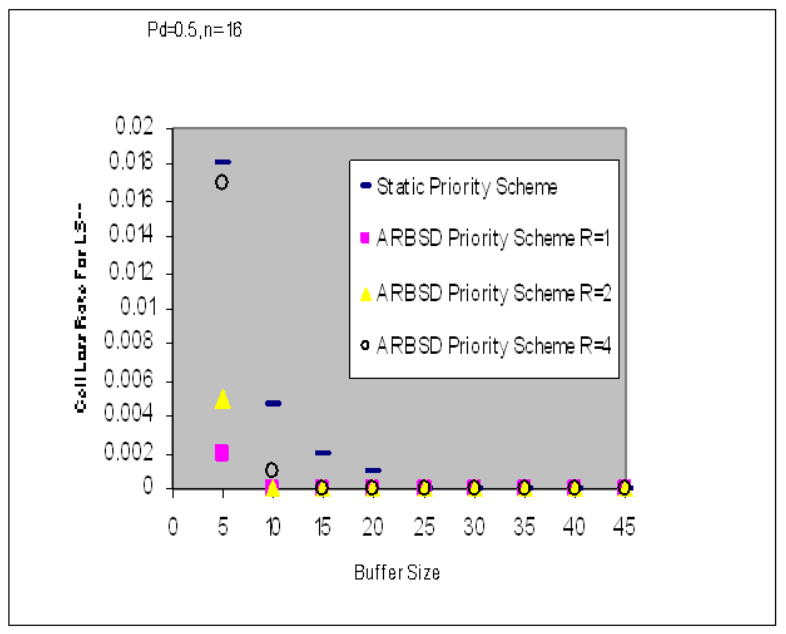

Figure 7 (a) Cell Loss Rate For Loss Sensitive Class Vs Buffer Size

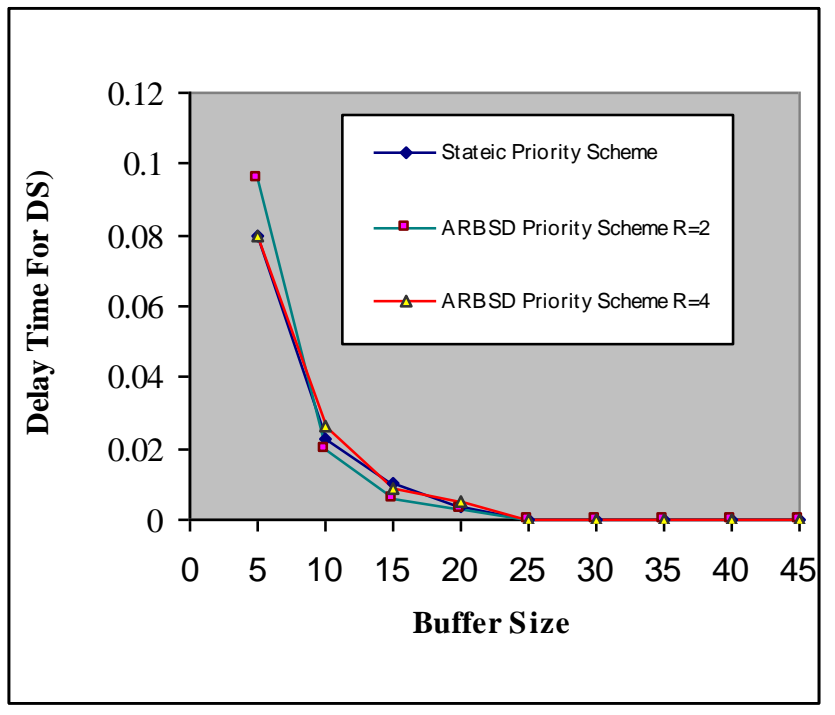

Fig. 7 (b) Cell Loss Rate For Delay Sensitive Class Vs Buffer Size 